\title{
COUNCIL AND BOARD OF TRUSTEES-1972
}

\section{CounciL}

\author{
President: Nathan Jacobson \\ President-elect: Saunders Mac Lane \\ Vice Presidents: \\ Richard D. Anderson \\ R. Creighton Buck \\ Edwin H. Spanier
}

\author{
Secretary: Everett Pitcher \\ Associate Secretaries: \\ Paul T. Bateman \\ Walter H. Gottschalk \\ Orville G. Harrold, Jr. \\ Kenneth A. Ross \\ Treasurer: W. T. Martin
}

\section{Publications Committees}
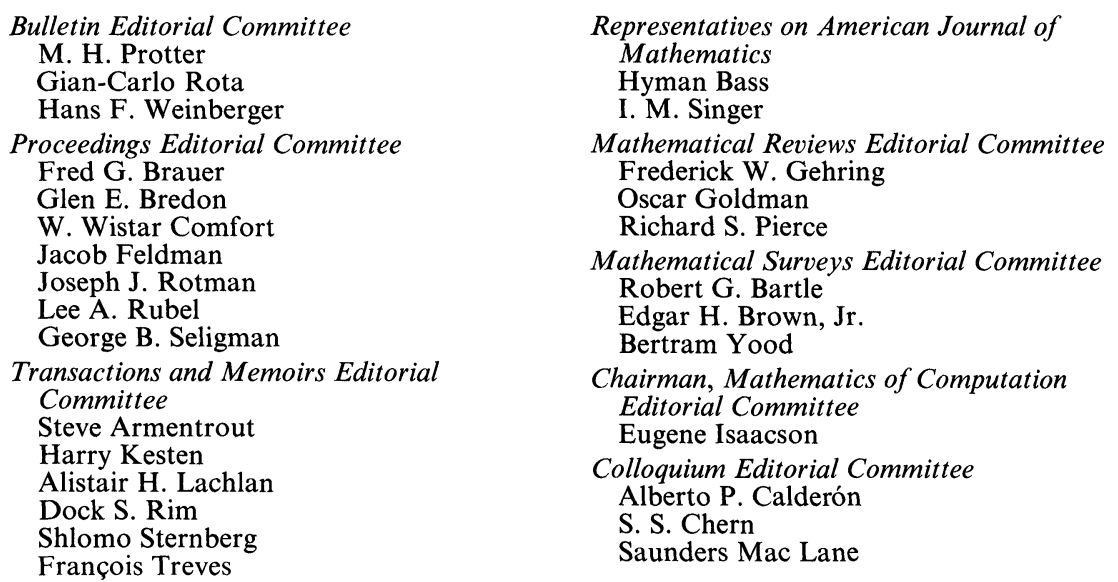

\section{Communications Committee \\ Committee to Monitor Problems in Communication Alex Rosenberg}

Members-At-Large

(Terms expire on January 31 of the given year.)

1972

Michael Artin

Michael F. Atiyah

Philip Hartman

C. C. Lin

Calvin C. Moore

Paul T. Bateman

Nathan Jacobson (ex officio)

Irving Kaplansky (chairman of the board)
1973

George F. Carrier

Morton L. Curtis

Mary Ellen Rudin

James B. Serrin

Elias M. Stein

\section{BOARD OF TRUSTEES}

Richard S. Palais

W. T. Martin (ex officio)
1974

William Browder P. S. Mostert Robert T. Seeley Dorothy Maharam Stone Olga Taussky Todd

Calvin C. Moore Murray H. Protter (assistant treasurer) 